\title{
Adopting Computer-Based Assessments: The Role of Perceived Value in Classroom
} Technology Acceptance

\author{
Joseph M. Sirianni, Niagara University, USA \\ Yu Jie Ng, Nanyang Technological University, Singapore \\ Arun Vishwanath, University at Buffalo, State University of New York, USA
}

\begin{abstract}
Computer based assessments (CBA) have increasingly become a popular tool for educators to test students' knowledge of course material because of the many advantages it confers. However, research on its perceived value and satisfaction among students has found mixed results, with some test takers' attitudes ranging from enthusiasm at being able to complete exams and retrieve test results whenever they want, to others actively disliking its use. As yet, the reasons for the same remain unclear. What is clear is that unmotivated or discontented students' negative evaluations of CBA could overtime lead to a discontinuance of its usage in classrooms. Understanding the drivers of students' continued usage of CBA is therefore key to the future use of this technological innovation and the goal of this research. To this end, the study utilized the Unified Theory of Acceptance and Use of Technology (UTAUT) - a model specifically built to understand the adoption of software technology - to the classroom adoption of technology context. Using quantitative survey data from 111 students who were assessed using CBAs, the study examined the role of the UTAUT constructs of performance expectancy, effort expectancy, social influence, and facilitating conditions in predicting students' continuance intention for CBA. Findings found a direct effect of UTAUT's core constructs of performance expectancy, social influence, and facilitating conditions on continuance CBA intention. Interestingly, students' perceived value of CBA partially mediated the effect of these constructs on continuance intention. The results of the study, therefore, point to a single, new, global construct-perceived value of CBA - that predicts whether students prefer classroom technology.
\end{abstract}

Keywords: UTAUT, CBA perceived value, computer-based assessment, technology acceptance, education 


\section{Introduction}

Thanks to global proliferation of the Internet, wide access of high-speed connectivity, and the availability of cheaper access devices, classrooms all over the world are rapidly adopting distancebased online education. Due to their invaluable source of information, computers have additionally played a significant role for feedback and assessment tools (McDonald, 2002). Inevitably this has necessitatedonline, computer-based assessments (CBA). While CBA enablesseveral conveniences overpaper and pen exams $(\mathrm{P} \& \mathrm{P})$ - not the least being the ease of its implementation across large, distributed users - it is of particular importance to understand whether its core users, i.e., students, see value in it. This is because if students believe that CBA is harder to accomplish, creates greater time pressures, and is unfair compared to $\mathrm{P} \& \mathrm{P}$, it could lead to them avoiding courses that utilize such testing. In other words, the very foundation of the movement towards offering courses online, which has led to benefits ranging from reducing the costs of conducting courses to the adoption of massive open online courses (Barkley 2002) and has been immensely beneficial for schools, colleges, and students all across the world (Bennett, 1998), is put at risk. Not just that, but student dislike might seep into their assessments of courses and course instructions that might lead to instructors or courses being discontinued.

Surprisingly few studies have, however, looked at the value of CBA. Those that have tend to focus only indirectly on testing and even these have found mixed results.Findings point to some students finding CBA testing to be more promising, credible, objective, fair, interesting, fun, fast, less difficult, and less stressful than P\&P tests (Croft, Danson, Dawson, \& Ward, 2001; Sambell, Sambell, \& Sexton, 1999), using adjectives such as "efficient,", “educational," "better," and "helpful" to describe CBA over P\&P exams, while other students appear to find such testing to be "impersonal", "less efficient" and "unclear" (Bouhnik \& Marcus, 2006). More importantly, these negative views appear to permeate to the students' dislike towards the very format of online education, with users complaining about their unfamiliarity with assessment design, delayed feedback from instructors, increased computer anxiety, and lack of technological support (Bugbee, 1996; Chua, Chen, \& Wong, 1999; Yang \& Cornelius, 2004).

Given the importance of users' attitudes and beliefs towards the intention to use CBA, the current paper extends the Unified Theory of Acceptance and Use of Technology (UTAUT) model—a model that tests the role of attitudes and beliefs on people's intention to use technology. UTAUT 
posits the user beliefs towards a technology's performance, the amount of effort it takes to use it, and how others who use the technology perceive it, directly determine intention to use the technology. The model focuses on attitudes and beliefs but does not, however, incorporate values, which influence people's behaviors by influencing their beliefs (Eccles \&Wigfield,1995). To examine the relative influence of both beliefs as well as values, the current study tests two models: UTAUT and the expectancy-value model of achievement. The next section begins with these theoretical frameworks.

\section{Theoretical Framework}

UTAUT (Venkatesh, Morris, Davis, \& Davis; 2003) integrates eight competing models of IT adoption, including the technology acceptance model (TAM) (Davis, 1986) and social cognitive theory (Bandura, 1986). The model predicts that performance expectancy, effort expectancy, and social influencedirectly determine intention to use a particular technology, and that facilitating conditions and intention directly predicts technology usage. According to a study by Venkatesh (2003), the theory has been found to explain $70 \%$ of the variance in users' likelihood to adopt information technologies. UTAUT specifically has been described as a robust and parsimonious model of individual IT acceptance (Chiu \& Wang, 2008) and has been tested on the acceptance and use of mobile services and web-based applications (Carlson et al., 2006; Cody-Allen \& Kishore, 2006; Wang \& Yang, 2005). These findings, therefore, make UTAUT an appropriate model to explore students' beliefs and intention to continue using CBA.

CBA fits into a larger category of education under web-based learning. This type of learning involves the communication of information through the Internet, intranet,or extranet for educational purposes (Chiu \& Wang, 2008). While no research directly examines student attitudes and intentions of using CBA, some other analogues exist. Previous work on webbased learning by Chiu and Wang (2008) utilized UTAUT to address students' attitudes towards web-based learning and their intention for continued use. Additionally, components of TAM that are now included under UTAUT, such as perceived ease of use and perceived usefulness, have been used in past studies to examine web-based learning acceptance (e.g., Liaw, 2008; Ong et al., 2004; Yi \& Hwang, 2003). Other studies have also isolated elements of UTAUT to predict acceptance and intention to use a learning system. For example, Teo(2009) incorporated facilitating conditions and social influence to explain teachers' attitudes towards computer use. Although UTAUT has 
not been used to examine CBA acceptance, it is reasonable to assume that the framework can be applied in examining students' preferences forCBA, based on findings in other forms of information technology. Terzis and Economides (2011) who proposed the computer based assessment acceptance model, did not specifically utilize UTAUT to explain CBA acceptance, but instead incorporated constructs of the theory of planned behavior (Ajzen, 1991), TAM and UTAUT.In that study, three constructs taken from UTAUT - perceived usefulness, facilitating conditions, and social influence - had indirect effects on intention to use CBA.

Previous studies have expanded on existing theories to explain continued usage of web-based learning technologies (e.g. Chiu, Hsu, Sun, Lin \& Sun, 2005; Chiu, Sun, Sun \&Ju, 2007; Lee, 2010, Limayem\& Cheung, 2008; Roca, Chiu \& Martinez, 2006). In particular, Chiu and Wang (2008) extended UTAUT by incorporating the construct of subjective task value (Eccles et al., 1983) in their model of web-based learning. According to Wigfield and Eccles (2000), an individual's choice, persistence, and performance are based on their beliefs for performing a behavior and how much they value that behavior.Eccles et al. (1983) adapted the expectancy value model by focusing on subjective task value to predict students' motivations and intentions to continue enrollment in specific school subjects. According to Dickhauser and Steinsmeir-Pelster (2003), the higher a student's expectations of success and perceived value in an activity, the more likely a student is to choose that activity. This study thus builds upon UTAUT by incorporating students' subjective task value into the theoretical framework. Subjective task value, now referred to as CBA perceived value, will be defined as the amount of value students attribute to using CBA.

\section{Current Study}

Advancements in classroom technology, specifically in the form of CBA, have grown over the years and a closer inspection of this area of education presently deserves special attention. Numerous researchers have examined students' attitudes towards using CB A exams; however, most of these studies have not applied a theoretical framework to analyze these attitudes. While researchers have reported students' general feelings towards CBA (i.e. interesting, fun, fast), scientific theories and models have largely been ignored. This study uses UTAUT to predict student's intention to continue using computer-based assessments. 
Previous studies have used UTAUT to explain web-based usage (e.g. Chiu \& Wang, 2008; Wang, Wu, \& Wang, 2009), but the majority of studies have largely ignored the framework of UTAUT as direct determinants in predicting students' intended CBA usage. The current study thus proposes a theoretical model using UTAUT to explain students' values, beliefs and intention towards using CBA. The next section presents the hypothesized relationships, along with the hypothesized model.

\section{Hypotheses}

Performance expectancy is the degree to which an individual believes that a system will help achieve gains by performing a specific task. It is defined as perceived usefulness in TAM. Previous studies have demonstrated a positive effect of perceived usefulness on behavioral intention to use a web-based learning system (e.g.Chiu \& Wang, 2008; Lee, 2008; Liaw, 2008; Ong \& Lai, 2006; Saade` \& BahliVanRaaij \& Schepers, 2008; Terzis \& Economides, 2011). According to Terzis and Economides (2011), students may find CBA useful in improving their knowledge, comprehension, and performance in their academic courses.Additionally, a study by Liaw (2008), reports that perceived usefulness was the most significant contributing factor to students' intention towards an e-learning system (58\%). In that study, students felt that interactivity, communicative functions, and activities were most important in regards to how useful they felt the system was. We therefore predict that the more useful students perceive CBA to be in academic performance, the more likely they will want to continue using CBA.

Effort expectancy is the extent to which an individual perceivesthe ease of usage with regard to a particular system. Under TAM, effort expectancy is defined as the perceived ease of use. Specifically, the easier a system is to use, the more likely an individual is to continue using that system. Prior research has demonstrated a positive relationship between perceived ease of use with technology and behavioral intention (Agarwak \& Prasad, 1999; Hu, Chau, Sheng, \& Tam, 1999; Terzis \& Economides, 2011; Venkatesh, 1999; Venkatesh \& Davis, 1996).Therefore, students who spend little to no effort completing CBA should thus be more likely to prefer CBA in the future.

The next determinant of behavioral intention under UTAUT is social influence. Social influence is the extent to which a user perceives the most important individuals in their social circle would 
support their use of a specific technology. Social influence includes the effect of other people's opinions, superior influence, and peer influence (Taylor \& Todd, 1995). Past research suggests that an individual's intent to perform a behavior is higher when those individuals in their social circle hold favorable opinions about that behavior (Ajzen, 1991). Several technology acceptance studies have incorporated social influence in their models to explain behavioral intention (e.g. Agarwal \& Karahanna, 2000; Karahanna \& Straub; Lu et al., 2003; Venkatesh \& Davis, 2000; Venkatesh et al., 2003) and Terzis and Economides (2011) suggest thatstudents who have never used CBA before may feel unsure about the technology, and will value the opinions of their close peers regarding CBA. Thus, students who believe that the strong ties within their social network will be supportive of the use of CBA will intent to continue with using CBA.

Facilitating conditions are the degree to which an individual believes that certain resources exist to support the use of a specific technology. Students should have access to available resources to help them with any issues they might experience while taking CBA. These resources may come in the form of an organizational staff or expert on the system (Bueno \& Salmeron, 2008). Bergeron et al. (1990) statedthat usage of a technology will increase as technological barriers are removed due to the presence of help and support. According to Triandis (1980), behavior to continue using a particular system will not occur if there are any impediments to available facilitating conditions. Therefore, students are more likely to achieve goals they may not have been able to meet on their own when they receive the support of peers as well as their instructors (Grabinger \& Dunlap, 2000). Under the current study, continuance intention to use CBA will be dependent on the available facilitating conditions within and outside of the Blackboard system. The following hypotheses are therefore proposed:

\section{H1a-d: Performance expectancy, effort expectancy, social influence, and facilitating conditions will be positively related to $\mathrm{CBA}$ continuance intention.}

As discussed by Chiu and Wang (2008), an individual who thinks a technological innovation is less beneficial will be less likely to continue using that innovation. Eccles and Wigfield (2002) state that an individual's motivation for performing a specific behavior is influenced by their expectancy for success and its subjective task value. Various elements of subjective task value exist, including interest in the task, importance of the task, and usefulness of the task (Eccles et al., 1983). Drawing upon previous work by Battle $(1965,1966)$, we define values as the personal 
importance of doing well on a task. This is similar to attainment value described by Eccles et al. (1983). Under the current study, subjective task value towards CBA will be referred to as CBA perceived value. We predict that individual'sexpectancies or perceptions for successfully achieving a task are directly dependent on how important they believe that task is. If an individual does not value the task at hand, then their expectancies for performing that task should be reduced. These findings lead us to believe that the higher the importance that is placed on CBA, the higher the expectancies and positive beliefs individuals will havefor achieving goals associated with CBA.

\section{H2a-d: CBA perceived value will be positively related to performance expectancy, effort expectancy, social influence, and facilitating conditions.}

Since our hypothesized model predicts a positive relationship from CBA perceived value to key variables in UTAUT, which lead to continuance usage, it is useful to explore whether the key variables in UTAUT mediates the relationship between CBA perceived value and continuance usage. We predict that values held about CBA will lead to positive beliefs about CBA, which in turn results in a motivational increase in continuing CBA usage. 
H3a-d: Performance expectancy, effort expectancy, social influence, and facilitating conditions will mediate the relationship between CBA value and continuance usage.

$\mathrm{H} 3 \mathrm{a}$

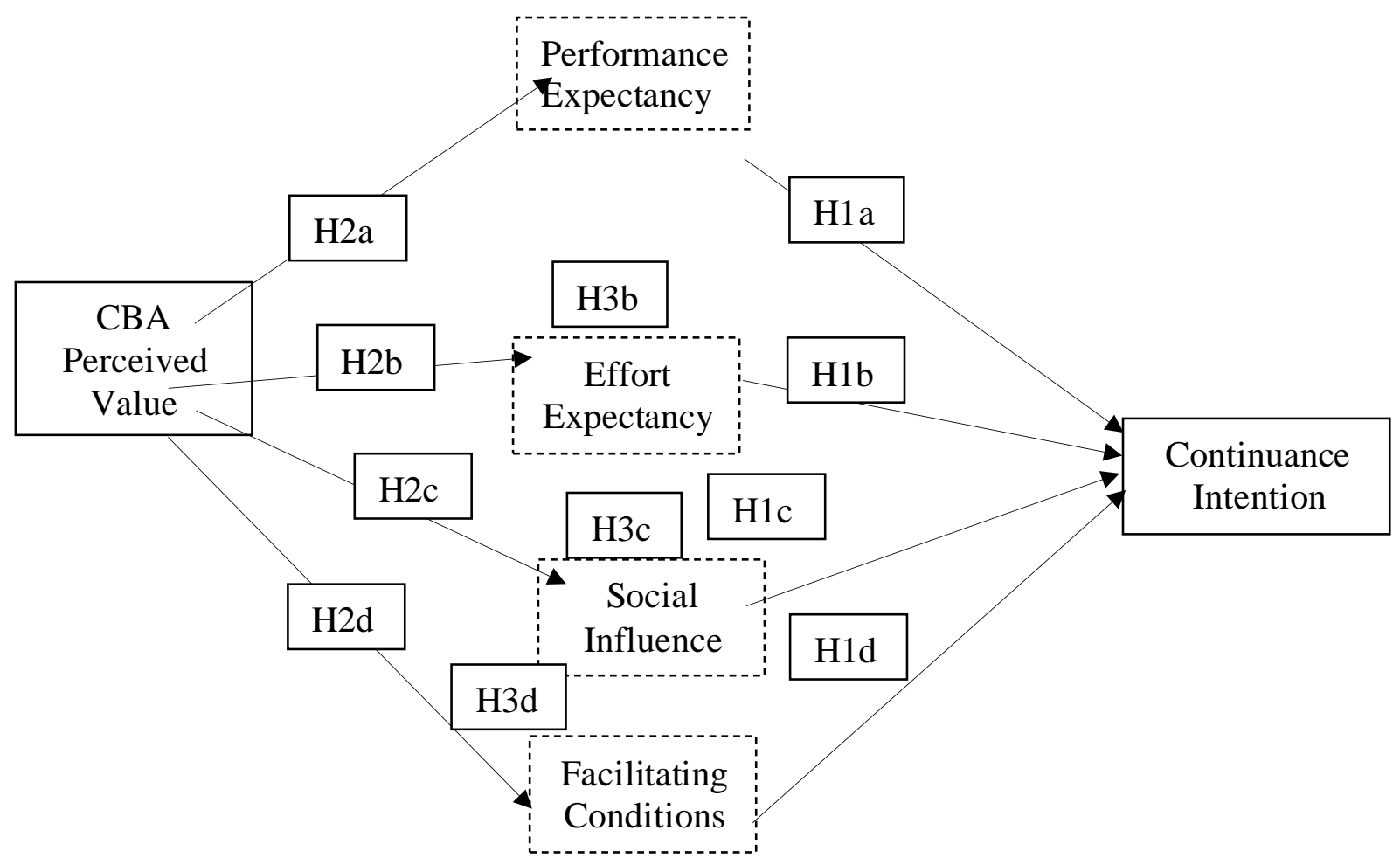

Note: Dotted lines indicate mediating variables for hypotheses 3a-d [Figure 1.

Hypothesized relationships of research model]

\section{Methods}

\section{Participants}

A total of 111 college students (44 men, 67 women) who were enrolled in a face-to-face introductory undergraduate communication course at a large university in Singapore participated in the study. All subjects received extra course credit for their participation. Subjects agreed to participation via an online consent form. Subjects were guaranteed complete anonymity, and the data collectedwere only accessible by the authors for the sole purpose of this study.

\section{Measures}

An online questionnaire was created as the instrumentfor data collection. At the end of their semester, students were administered an unsupervised, online final exam as part of their course requirements.The final exam wasadministered using the Blackboard Learning System. 
Blackboard is a web-based learning management system that provides various educational tools, including CBA, for educators and students. Following completion of the exam, students were emailed a link to the survey and given one week to complete it. The survey questions were designed to measure students' perceptions of taking a CBA exam on Blackboard, as well as their likelihood to continue using CBA in the future.

The majority of constructs in the study were measured using 5-point Likert type scales ranging from 1 ('strongly disagree') to 5 ('strongly agree'), unless otherwise noted. Wherever possible, the scales used for the instrument were taken from previously validated measures, reworded, and designed to fit the context of the study. Both performance expectancy and effort expectancy were measured using four items previously created by Venkatesh et al. (2003). Social influence was measured using two items, and facilitating conditions was measured using four items, all adapted from Venkatesh et al. (2003). To measure the construct of CBA perceived value, we used four items adapted by Eccles et al. (1983), in addition to five new items created by the authors, for a total of nine items. Finally, CBA continuance intentionwas measured usingthree items created by Bhattacherjee (2001). All constructs achieved had high Cronbach's alpha (> .90), indicating good internal consistency.

\section{Data Analysis}

Partial least square structural equation modeling (PLS-SEM) analysis was used to estimate the measurement model using Smart PLS software (Ringle et al., 2013). PLS-SEM is similar to covariance structural equation modeling (CB-SEM) techniques in that it uses multiple regressions to predict the values for latent variables and explicitly recognizes measurement error (Bhakar et al, 2012; Chin \& Newsted, 1999; Fornell \& Cha, 1994; Chin, 1998; Fornell \& Bookstein, 1982). On the other hand, PLS-SEM is less restrictive than CB-SEM and can be used with smaller sample sizes with constructs containing fewer items (Fornell \& Cha, 1994; Henseler et al., 2014; Reinartz, 2009). In regards to sample size, previous technology adoption studies using PLS have found significant results for smaller sample sizes (So \& Bolloju, 2005; Venkatesh \& Davis, 2000). Pertinent to this study, several researchers have also used PLS to examine technology acceptance on learning systems (e.g. Han, 2003; Hsu, Chen, Chiu, \&Ju, 2007; Terzis \& Economides, 2011; Yi \& Hwang, 2003). Unlike CB-SEM, however, PLS does not employ a goodness-of-fit measure. While past researchers have proposed a GOF measure for PLS-SEM (Tenenhaus et al., 2004), research showed that the measure is unsuitable for identifying misspecified models (Henseler and 
Sarstedt, 2012). Researchers using PLS-SEM are therefore encouraged to rely on measures indicating the model's predictive capabilities to assess the model's quality (Henseler et al., 2014).

\section{Convergent Validity}

Three criterion indicated by Fornell and Larcker (1981) and Teo (2009) are used to determine a measurement model's convergent validity: (1) factor loadings on all indicator items exceed 0.70 , (2) composite reliability of each construct exceeds 0.70 and (3) the average variance extracted (AVE) exceeds a cut-off of 0.50 . All criteria were satisfied and confirms the measurement model's convergent validity. Results for the convergent validity test indicated that the AVE for the five scales ranged from 0.60 to 0.85 , which satisfies the cut-off value of .50 as set by Fornell and Larcker (1981). These findings support the notion that all items are related to their respected constructs. Means, standard deviations, individual factor loadings, Cronbach's alpha, composite reliabilities, and average variance extracted values can be found in Table $\mathbf{1}$. 
Table 1. Means, standard deviations, factor loadings, cronbach's alpha, composite reliabilities, and AVE of constructs

\begin{tabular}{|c|c|c|c|c|c|c|}
\hline \multirow[t]{2}{*}{ Mean Standard } & \multirow[t]{2}{*}{ Factor } & \multicolumn{2}{|c|}{ Cronbach's } & \multirow{2}{*}{$\begin{array}{l}\text { Composite } \\
\text { Alpha }\end{array}$} & \multirow{2}{*}{$\begin{array}{l}\text { AVE } \\
\text { Reliability }\end{array}$} & \\
\hline & & Deviation & Loading & & & \\
\hline Performance Expectancy & 3.94 & 0.69 & & 0.90 & 0.94 & 0.78 \\
\hline PE_1 & & & 0.89 & & & \\
\hline PE_2 & & & 0.87 & & & \\
\hline PE_3 & & & 0.88 & & & \\
\hline PE_4 & & & 0.86 & & & \\
\hline Effort Expectancy & 4.33 & 0.57 & & 0.93 & 0.93 & 0.77 \\
\hline EE_1 & & & 0.87 & & & \\
\hline EE_2 & & & 0.86 & & & \\
\hline EE_3 & & & 0.90 & & & \\
\hline EE_4 & & & 0.87 & & & \\
\hline Social Influence & 3.41 & 0.77 & & 0.93 & 0.96 & 0.93 \\
\hline SI_1 & & & 0.96 & & & \\
\hline SI_2 & & & 0.97 & & & \\
\hline Facilitating Conditions & 4.37 & 0.56 & & 0.91 & 0.94 & 0.85 \\
\hline FC_1 & & & 0.92 & & & \\
\hline FC_2 & & & 0.93 & & & \\
\hline $\mathrm{FC} \_3$ & & & 0.91 & & & \\
\hline CBA Value & 3.67 & 0.71 & & 0.93 & 0.94 & 0.64 \\
\hline $\mathrm{CV}_{-} 1$ & & & 0.83 & & & \\
\hline $\mathrm{CV} \_2$ & & & 0.81 & & & \\
\hline $\mathrm{CV}_{-} 3$ & & & 0.77 & & & \\
\hline $\mathrm{CV}_{-} 4$ & & & 0.80 & & & \\
\hline CV_5 & & & 0.74 & & & \\
\hline CV_6 & & & 0.74 & & & \\
\hline $\mathrm{CV}_{-} 7$ & & & 0.87 & & & \\
\hline CV_8 & & & 0.83 & & & \\
\hline CV_9 & & & 0.80 & & & \\
\hline Continuance Intention & 4.09 & 0.75 & & 0.91 & 0.94 & 0.84 \\
\hline CI_1 & & & 0.93 & & & \\
\hline CI_2 & & & 0.93 & & & \\
\hline CI_3 & & & 0.90 & & & \\
\hline
\end{tabular}

\section{Discriminant Validity}

Tests for discriminant validity satisfied both criterion described by Chin (1998) and Bhakar et al. (2012). All constructs had an AVE loading greater than 0.5 and all values reported in the table were significantly higher than the off-diagonal values in the corresponding rows and columns. 
The confirmation of both criteria lends evidence that the constructs vary adequately and distinctively. Discriminant validity results can be found in Table 2.

Table 2. Discriminant validity for measurement model

\begin{tabular}{llllllll}
\hline Construct & BI & EE & FC & PE & SI & CV \\
\hline BI & $\mathbf{0 . 9 2}$ & & & & & \\
EE & 0.5265 & $\mathbf{0 . 8 7 8}$ & & & & \\
FC & 0.5537 & 0.6868 & $\mathbf{0 . 9 2}$ & & & & \\
\hline & & & & & & \\
\hline PE & 0.6685 & 0.6046 & 0.4231 & $\mathbf{0 . 8 8 5}$ & & \\
SI & 0.4986 & 0.2917 & 0.2444 & 0.478 & $\mathbf{0 . 9 6 4}$ & \\
CV & 0.6888 & 0.4476 & 0.3525 & 0.7316 & 0.5433 & $\mathbf{0 . 8 0 1}$ \\
\hline
\end{tabular}

\section{Results Structural Model Analysis}

To test the significance of our hypotheses and t-values under PLS-SEM, calculations were performed using the bootstrapping procedure. This method allows analysis of up to 200 indicator variables, which provides examination amongst the interactions of moderator and latent variable predictors (Al-Gahtani et al., 2007). Specifically, the structural model and hypotheses were tested by computing path coefficients ( $\beta$ ). Because PLS-SEM does not require normally distributed data like CB-SEM, it is evaluated with R-squared calculations for dependent variables (Bhakar et al, 2012; Cohen 1988).

Overall, the model predicted $58 \%$ of the variance in the dependent variable (continuance intention to use CBA). The variables explained for each of the endogenous variables were as followed: performance expectancy $\left(\mathrm{R}^{2}=.534\right)$, effort expectancy $\left(\mathrm{R}^{2}=.200\right)$, social influence $\left(\mathrm{R}^{2}=.299\right)$, and facilitating conditions $\left(\mathrm{R}^{2}=.124\right)$. The hypothesized relationships, their tvalues, path coefficients, and p-values can be found in Table 3 . 
Table 3. T-values and path coefficients of hypothesized relationships

\begin{tabular}{lllll}
\hline Hypotheses & Path & & T-Values & Path \\
& & & Coefficients \\
\hline H1a & $\begin{array}{l}\text { Performance } \\
\text { expectancy } \rightarrow\end{array}$ & Continuance intention & $4.751^{* * *}$ & 0.437 \\
H1b & Effort expectancy $\rightarrow$ & Continuance intention & 0.136 & -0.015 \\
H1c & Social influence $\rightarrow$ & Continuance intention & $3.668^{* * *}$ & 0.239 \\
H1d & Facilitating conditions $\rightarrow$ & Continuance intention & $3.033^{* *}$ & 0.301 \\
H2a & CBA value $\rightarrow$ & Performance expectancy & $12.694 * * *$ & 0.731 \\
H2b & CBA value $\rightarrow$ & Effort expectancy & $4.742^{* * *}$ & 0.447 \\
H2c & CBA value $\rightarrow$ & Social influence & $7.533^{* * *}$ & 0.548 \\
H2d & CBA value $\rightarrow$ & Facilitating conditions & $3.621 * * *$ & 0.353 \\
\hline
\end{tabular}

$* * \mathrm{p}<0.01 ; * * * \mathrm{p}<0.001$

Hypothesis 1a predicted a positive relationship between performance expectancy and continuance intention. This relationship was supported. Hypothesis $1 \mathrm{~b}$ predicted a positive relationship between effort expectancy and continuance intention. This relationship was not supported. A positive relationship between social influence and continuance intention was predicted for hypothesis 1c. This relationship was confirmed. The relationship between facilitating conditions and continuance intention for hypothesis $1 \mathrm{~d}$ was also supported.

Hypothesis 2 a predicted a positive relationship between CBA perceived value and performance expectancy. This relationship was supported. A positive relationship between CBA value and effort expectancy was predicted for hypothesis $2 b$. This relationship was supported. Hypothesis 2c predicted a positive relationship between CBA perceived value and social influence. This relationship was also supported. A positive relationship between CBA perceived value and facilitating conditions was predicted and supported for hypothesis $2 \mathrm{~d}$.

\section{Mediation Analysis}

The mediated relationships were tested using the statistical method of Preacher and Hayes (2008). This approach was applied to calculate the total, direct, and indirect effects, in addition to the $95 \%$ confidence interval for the mediated variables. Figure 2 (A) displays the total effects of CBA perceived value on CBA continuance intention $(c)$ whereas Figure $2(B)$ displays the full mediated 
model with the direct effect of CBA perceived value on CBA continuance intention $\left(c^{\prime}\right)$. The relationships, $c$ and $c$ 'were not hypothesized in the structural model, however, they are included here to test for partial or full mediation (Baron \& Kelly, 2006).

\section{A. Model with total effect}

$$
\mathrm{c}=.73^{* * *}
$$

\begin{tabular}{|c|c|c|}
\hline CBA \\
Value
\end{tabular}

\section{B. Model with direct effects}

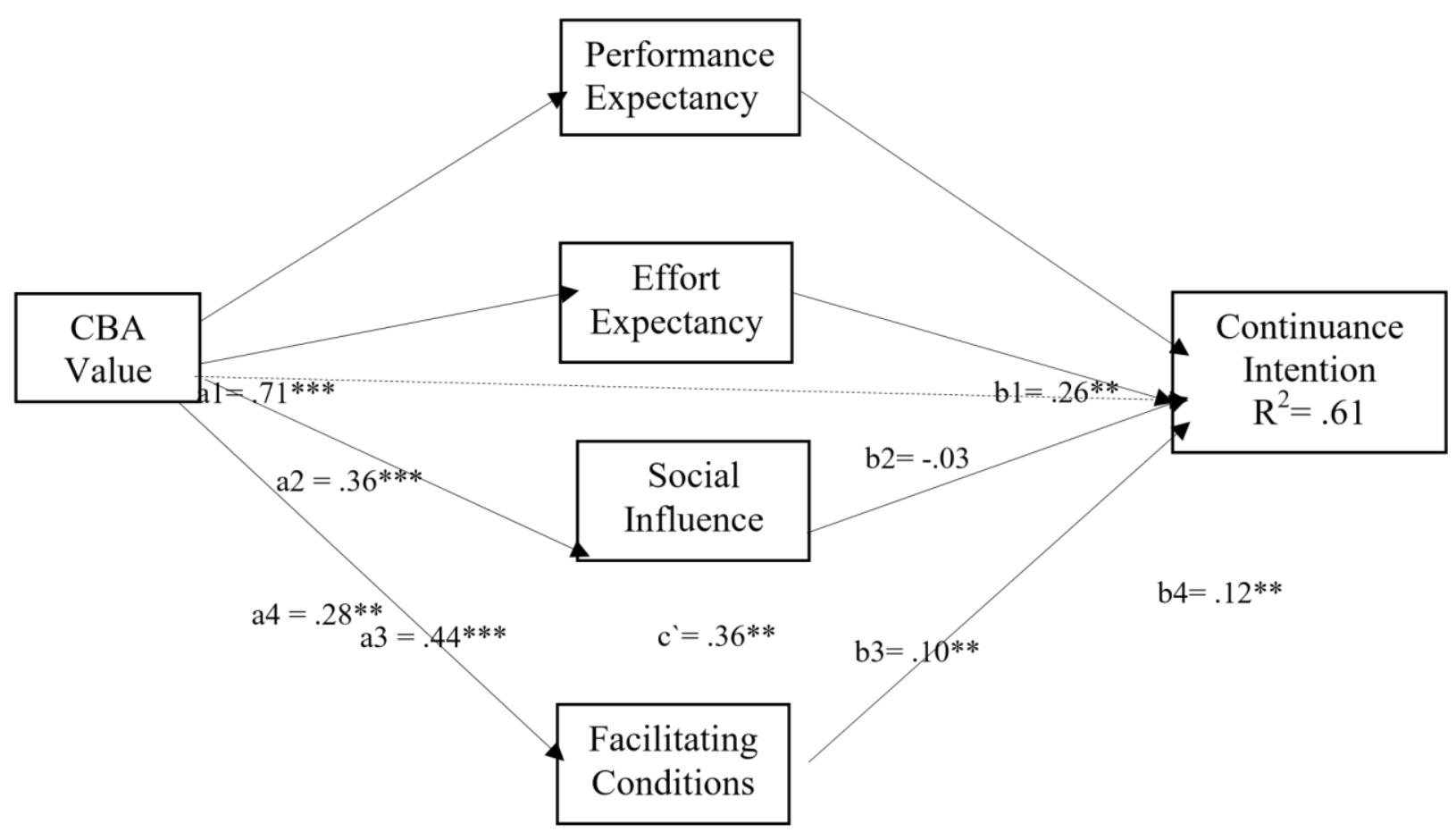

Figure 2. Summary of mediating effects test

In accordance with Preacher and Hayes (2008), indirect effects were tested using the bootstrapping method. Compared to the traditional Sobel test, bootstrapping the sampling distribution for indirect effects works for simple and multiple mediation models, does not require variable or sampling distributional assumptions, and can be applied to smaller samples with more confidence (see Hair et al., 2013). Moreover, past researchers have also used the Preacher and Hayes method in conjunction with PLS-SEM to test for both significance and mediation effects (e.g. Castro \& 
Roldan, 2013; Real, Roldan, \& Leal, 2014; Wellner, 2015).According to Chin (2010) there are two-steps for testing mediation in PLS:

(1) Performing $\mathrm{N}$ bootstrap re-samplings on the proposed model for both direct and indirect paths, and explicitly calculate the product of the direct paths that form the indirect path under assessment, followed by (2) Estimating the significance using percentile bootstrap (Williams \& MacKinnon, 2008). This process produces a $95 \%$ confidence interval for mediators: performance expectancy (H3a), effort expectancy (H3b), social influence (H3c), and facilitating conditions (H3d).Intervals for the mediation hypotheses in this study that do not contain zero, demonstrates that the indirect effect differs significantly from zero with $95 \%$ confidence.

Results of the analysis show that CBA perceived value has a significant total effect on CBA continuance intention. CBA perceived value retains its significance when adding the mediators to the model, hence, indicating that the mediators partially mediate the relationship between CBA perceived value and continuance intention. Indirect effects results show that performance expectancy mediates the relationship between CBA perceived value and continuance intention. Results also show that social influence mediates the relationship between CBA perceived value and continuance intention. Finally, results show that facilitating conditions mediates the relationship between CBA perceived value and continuance intention. The results for total effects, direct effects, and indirect effects can be found in Table 4. 
Table 4. Results for total effects, direct effects, and indirect effects

\begin{tabular}{|c|c|c|c|c|c|c|c|}
\hline Total & & Direct & & Indirect & & & \\
\hline effect of & & effect of & & effects & & & \\
\hline CBA value & & CBA value & & of & & & \\
\hline on CBA & & on CBA & & $\mathrm{CBA}$ & & & \\
\hline \multirow[t]{3}{*}{$\mathrm{CI}(\mathrm{c})$} & & $\mathrm{CI}\left(\mathrm{c}^{\prime}\right)$ & & value & & & \\
\hline & & & & on & & & \\
\hline & & & & $\begin{array}{l}\text { CBA } \\
\mathrm{CI}\end{array}$ & & & \\
\hline \multirow[t]{3}{*}{ Coefficient } & $\mathrm{T}$-value & Coefficient & Tvalue & & Beta & $\begin{array}{l}\text { Bias } \\
\text { corrected } \\
\text { confidence } \\
\text { interval }\end{array}$ & $\begin{array}{l}\text { Percentile } \\
95 \% \\
\text { confidence } \\
\text { intervals }\end{array}$ \\
\hline & & & & & & Lower & Lower \\
\hline & & & & & & Upper & Upper \\
\hline \multirow[t]{5}{*}{0.73} & $13.02 * * *$ & 0.36 & $3.56 * *$ & Total & .3646 & $\begin{array}{l}.1884- \\
.5625\end{array}$ & $\begin{array}{l}.1753- \\
.5465\end{array}$ \\
\hline & & & & PE & .1815 & $\begin{array}{l}.0181- \\
.5625\end{array}$ & $\begin{array}{l}.0058- \\
.3541\end{array}$ \\
\hline & & & & $\mathrm{EE}$ & $\begin{array}{l}- \\
.0004\end{array}$ & $\begin{array}{l}-.0973- \\
.1103\end{array}$ & $\begin{array}{l}-.0881- \\
.1232\end{array}$ \\
\hline & & & & SI & .0879 & $\begin{array}{l}.0153- \\
.1774\end{array}$ & $\begin{array}{l}\text { 0100. - } \\
1709\end{array}$ \\
\hline & & & & $\mathrm{FC}$ & .0955 & $\begin{array}{l}.0262- \\
.2520\end{array}$ & $\begin{array}{l}.0164- \\
.2160\end{array}$ \\
\hline
\end{tabular}

$* * \mathrm{p}<0.01 ; * * * \mathrm{p}<0.001$

Note: CI indicates continuance intention

\section{Discussion}

This study sought to explain students' intention to continue using computer-based assessments through the framework of the unified theory of acceptance and use of technology. Our model successfully affirms the UTAUT framework and also confirms the role that value plays in predicting beliefs about CBA. Results support the structure of the model and support the key findings of H1a, H1c, H1d, H2a, H2b, H2c, H2d, H3a, H3c, and H3d: Performance expectancy predicted CBA continuance usage; social influence also predicted CBA continuance usage as did facilitating conditions; CBA perceived value predicted performance expectancy, effort expectancy, social influence, and facilitating conditions; performance expectancy, social influence, and facilitating conditions all had indirect effects on the relationship between CBA 
value and continuance intention. As predicted, performance expectancy was positively related to CBA intention. Of the three other determinants of UTAUT, performance expectancy had the strongest effect and highest $\mathrm{R}^{2}$ value on students' intention to continue using CBA. This is an interesting finding, since students believe that taking a CBA is most useful in increasing their academic performance for taking exams. Furthermore, students placed more value on performance expectancy than the other components of UTAUT. These findings led to the conclusion that the more value students place on CBA, the more likely they are to believe CBA are useful for their academic performance, and the more likely they are to continue using CBA.

Contrary to what was predicted, effort expectancy was not positively related to CBA continuance intention. One explanation for this finding could be that college students are already familiar with web-based learning systems, thus resulting in a lack of variance. College students continue to be early adopters of new Internet tools and applications in comparison to the general U.S. Internetusing population (Jones, Johnson-Yale, Millermaier, \& Perez 2009, Author \& Goldhaber, 2003). The effort for completing CBA most likely comes from post-use technology experience whereas the other components of UTAUT are apriori based. Interestingly, CBA perceived value was positively related to effort expectancy. This finding suggests that students who place more value on CBA will extend little effort in using the system. Social influence was found to have a direct positive effect on CBA continuance intention which supports the notion that students' intention to use CBA is strongly influenced by the perceptions of important others. Additionally, perceived value was positively related to social influence, and social influence also mediated the relationship between perceived value and continuance usage. Based on these results, it can be confirmed that when students value CBA, their beliefs for using CBA will be strongly influenced by important people around them, which will most likely lead to intentions to continue using CBA.

Finally, facilitating conditions was positively related to CBA continuance intention. This finding implies that students will be more likely to adopt CBA when there are available resources through either the online system or academic staff. CBA value was also positively related to facilitating conditions, and facilitating conditions mediated the relationship between CBA value and continuance intention. It can be concluded that students who value CBA are more likely to recognize the available resources necessary to use CBA and ultimately lead to their continued CBA usage in the future. 


\section{Limitations and Future Research}

The results of this study have provided new findings for explaining CBA usage among college students; however, several limitations should be addressed. First, our study does not account for a diverse group of learners. The sample consisted of purely undergraduate students from Singapore. Therefore, future studies should consider using students from other countries as subjects. The information reported here could also be useful for a cross-cultural study down the road. Additionally, our study only utilized a single web-based learning system, the Blackboard. Future studies might consider using other web-based learning systems independently or in conjunction with Blackboard. Next, our results revealed that effort expectancy was not positively related to CBA continuance intention. It is most likely that our sample thus consisted of students who were already familiar with web-based systems and CBA. The results, therefore, might not reflect novice users who have different values and beliefs towards CBA. Future studies may consider examining students who have never used a web-based system or completed a CBA before. Finally, the administering of a P\&P exam was not included in this study. It would be particularly informative to compare the grade scores of both types of assessments to garner any significant differences between them. Such comparisons will allow us to test if issues related to assessment, such as fairness, difficulty of exam, etc., are accounted and controlled for.

Overall, this study is noteworthy because it provides a framework for assessing CBA usage using a theoretical model. Most importantly, it extends the framework of UTAUT by incorporating the construct of perceived value to explain CBA usage. Future studies using UTAUT to explain technological educational assessments should consider the effect that perceived value has on continuance intention. Lastly, our research provides beneficial insight for educators who incorporate CBA into their course curriculum. 


\section{References}

Ajzen, I. (1991). The theory of planned behavior. Organizational behavior and human decision processes, 50, 179-211.

Akdemir, O., \& Oguz, A. (2008). Computer-based testing: An alternative for the assessment of Turkish undergraduate students. Computers \& Education, 51, 1198-1204.

American Psychological Association. Committee on Professional Standards, American Psychological Association. Board of Scientific Affairs.Committee on Psychological Tests, \& Assessment.(1986). Guidelines for computer-based tests and interpretations. The Association.and Achievement Motivation, W.H. Freeman, San Francisco, CA, 1983, pp. 75-146.

Bandura, A. (1986). Social foundations of thought and action. Englewood Cliffs, NJ, 1986.

Barkley, A. P. (2002). An analysis of online examinations in college courses. Journal of Agricultural and Applied Economics, 34, 445-458.

Bouhnik, D., \& Marcus, T. (2006). Interaction in distance-learning courses. Journal of the American Society for Information Science and Technology, 57(3), 299-305.

Bransford, J. D., Brown, A. L., \& Cocking, R. R. (1999). How people learn: Brain, mind, experience, and school. National Academy Press.

Bugbee, A. C. (1996). The equivalence of paper-and-pencil and computer-based testing. Journal of research on computing in education, 28, 282-299.

Bugbee, A. C. (1992). Examination on demand: Findings in ten years of testing by computer 1982-1991. Edina, MN: TRO Learning

Bugbee, A. C., \& Bernt, F. M. (1990). Testing by computer: Findings in six years of use 1982-1988. Journal of Research on Computing in Education, 23(1), 87-100.

Bunderson, C. V., Inouye, D. K., \& Olsen, J. B. (1989). The four generations of computerized educational measurement. In R. L. Linn (Ed.), Educational measurement (3rd ed.), (pp. 367-407 New York: American Council on Education--Macmillan.

Carlsson, C., Carlsson, J., Hyvonen, K., Puhakainen, J., \& Walden, P. (2006). Adoption of mobile devices/services—-searching for answers with the UTAUT. In Proceedings of the 39th Hawaii International Conference on System Sciences.

Castro, I., \& Roldán, J. L. (2013). A mediation model between dimensions of social capital. International Business Review, 22(6), 1034-1050. 
Chiu, C. M., Hsu, M. H., Sun, S. Y., Lin, T. C., \& Sun, P. C. (2005). Usability, quality, value and e-learning continuance decisions. Computers \& Education, 4, 399416.

Chiu, C. M., Sun, S. Y., Sun, P. C., \&Ju, T. L. (2007).An empirical analysis of the antecedents of web-based learning continuance. Computers \& Education, 49, 12241245.

Chiu, C. M., \& Wang, E. T. (2008). Understanding Web-based learning continuance intention: The role of subjective task value. Information \& Management, 45, 194201.

Chua, S. L., Chen, D. T., \& Wong, A. F. (1999). Computer anxiety and its correlates: a metaanalysis. Computers in human behavior, 15(5), 609-623.

Clariana, R., \& Wallace, P. (2002). Paper-based versus computer-based assessment: key factors associated with the test mode effect. British Journal of Educational Technology, 33, 593-602.

Cody-Allen, E., \& Kishore, R. (2006, April). An extension of the UTAUT model with equality, trust, and satisfaction constructs. In Proceedings of the 2006 ACM SIGMIS CPR conference on computer personnel research: Forty four years of computer personnel research: achievements, challenges \& the future(pp. 82-89). ACM.

Croft, A. C., Danson, M., Dawson, B. R., \& Ward, J. P. (2001). Experiences of using computer assisted assessment in engineering mathematics. Computers \& Education, 37, 53-66.

Davis, F. D. (1989). Perceived usefulness, perceived ease of use, and user acceptance of information technology. MIS quarterly, 13, 319-340.

DeAngelis, S. (1999). Equivalency of computer-based and paper-and-pencil testing. Journal of Allied Health, 29, 161-164.

Dickhauser, O., \& Stiensmeier-Pelster, J. (2003). Gender differences in the choice of computer courses: Applying the expectancy-value model. Social Psychology of Education, 6, 173-189.

Eccles, J. S., Adler, T. F., Futterman, R., Goff, S. B., Kaczala, C. M., Meece, J. L., \& Midgley, C. (1995). Expectancies, values, and academic behaviors. In J.T. Spence (Ed.), Achievement. 
Eccles, J. S., \& Wigfield, A. (1995). In the mind of the actor: The structure of adolescents' achievement task values and expectancy-related beliefs.

Fulcher, G. (2000). The 'communicative'legacy in language testing. System, 28, 483-497.

Harmon, O. R., \&Lambrinos, J. (2008). Are online exams an invitation to cheat?. The Journal of Economic Education, 39, 116-125.

Homer, P. M., \&Kahle, L. R. (1988). A structural equation test of the value-attitude-behavior hierarchy. Journal of Personality and social Psychology,54(4), 638.

Howell, S. L., Sorensen, D., \& Tippets, H. R. (2009).The new (and old) news about cheating for distance educators. Online Journal of Distance Learning Administration, 12.

Jones, S., Johnson-Yale, C., Millermaier, S., \& Pérez, F. S. (2009). US college students' Internet use: Race, gender and digital divides. Journal of Computer-Mediated Communication, 14, 244-264.

Kennedy, K., Nowak, S., Raghuraman, R., Thomas, J., \& Davis, S. F. (2000). Academic dishonesty and distance learning: Student and faculty views. College Student Journal, 34, 309-314.

Krsak, A. (2007). Curbing academic dishonesty in online courses. In TCC-Teaching Colleges and Community Worldwide Online Conference , 1, 159-170.

Liaw, S. S. (2008). Investigating students' perceived satisfaction, behavioral intention, and effectiveness of e-learning: A case study of the Blackboard system. Computers \& Education, 51(2), 864-873.

Limayem, M., \& Cheung, C. M. K. (2011). Predicting the continued use of Internet based learning technologies: the role of habit. Journal of Behaviour and Information Technology, 30(1), 91-99.

Mason, B. J., Patry, M., \&Berstein, D. J. (2001). An examination of the equivalence between non-adaptive computer-based and traditional testing.Journal of Educational Computing Research, 24, 29-40.

Mazzeo, J., \& Harvey, A.L. (1988).The equivalence of scores from automated and conventional educational and psychological tests (College Board Report No. 88-8). New York: College Entrance Examination Board.

McDonald, A. S. (2002). The impact of individual differences on the equivalence of computer-based and paper-and-pencil educational assessments. Computers \& Education, 39(3), 299-312. 
Mills, J. D. (2002). Using computer simulation methods to teach statistics: A review of the literature. Journal of Statistics Education, 10, 1-20.

Moran, M., Hawkes, M., \& El Gayar, O. (2010). Tablet personal computer integration in higher education: Applying the unified theory of acceptance and use technology model to understand supporting factors. Journal of Educational Computing Research, 42, 79-101.

Ogilvie, R. W., Trusk, T. C., \& Blue, A. V. (1999).Students' attitudes towards computer testing in a basic science course. Medical education, 33(11), 828-831.

Olsen, B., \& Krendl, K. A. (1990). At-risk students and microcomputers: What do we know and how do we know it? Journal of Educational Technology Systems, 19(2), 165175 .

Ramos, M. (2003).Auditors' responsibility for fraud detection. Journal of Accountancy, 195(1), 28-35.

Real, J. C., Roldán, J. L., \& Leal, A. (2014). From entrepreneurial orientation and learning orientation to business performance: analysing the mediating role of organizational learning and the moderating effects of organizational size. British Journal of Management, 25(2), 186-208.

Roca, J. C., Chiu, C. M., \& Martinez, F. J. (2006). Understanding e-learning continuance intention: an extension of the technology acceptance model. International Journal of Human-Computer Studies, 64(8), 683-696.

Sambell, K., Sambell, A., \& Sexton, G. (1999). Student perceptions of the learning benefits of computer-assisted assessment: A case study in electronic engineering. S. Brown, P. Race, \& J. Bull, Computer-assisted assessment in higher education, 179-191.

Schaeffer, G. A., Reese, C. M., Steffen, M., McKinley, R. L., \& Mills, C. N. (1993).Field test of a computer-based gre general test. ETS Research Report Series, 1993, 1-47.

Singleton, C., Horne, J., \& Thomas, K. (1999).Computerised baseline assessment of literacy. Journal of Research in Reading, 22(1), 67-80.

Stuber-McEwen, D., Wiseley, P., and Hoggatt, S. (2009). Point, click, and cheat: Frequency and type of academic dishonesty in the virtual classroom. Online Journal of Distance Learning Administration 12, 1-10.

Terzis, V., \& Economides, A. A. (2011). The acceptance and use of computer based assessment. Computers \& Education, 56, 1032-1044. 
Terzis, V., Moridis, C. N., \& Economides, A. A. (2013). Continuance acceptance of computer based assessment through the integration of user's expectations and perceptions. Computers \& Education, 62, 50-61.

Venkatesh, V., Morris, M. G., Davis, G. B., \& Davis, F. D. (2003). User acceptance of information technology: Toward a unified view. MIS quarterly, 425-478.

Vishwanath, A., \& Goldhaber, G. M. (2003). An examination of the factors contributing to adoption decisions among late-diffused technology products. New media \& society, $5,547-572$.

Wang, H. I., \& Yang, H. L. (2005).The role of personality traits in UTAUT model under online stocking. Contemporary Management Research, 1(1), 69-82.

Watson, G. R., \& Sottile, J. (2010). Cheating in the digital age: Do students cheat more in online courses?.

Wellner, K. (2015). Contribution and Implications.In User Innovators in the Silver Market (pp. 170-178). Springer Fachmedien Wiesbaden.

Wise, S. L., \& Plake, B. S. (1989).Research on the effects of administering tests via computers. Educational measurement: Issues and practice, 8, 5-10.

Yang, Y., \& Cornelius, L. F. (2004). Students' Perceptions towards the Quality of Online Education: A Qualitative Approach. Association for Educational Communications and Technology.

results for total effects, direct effects, and indirect effects 